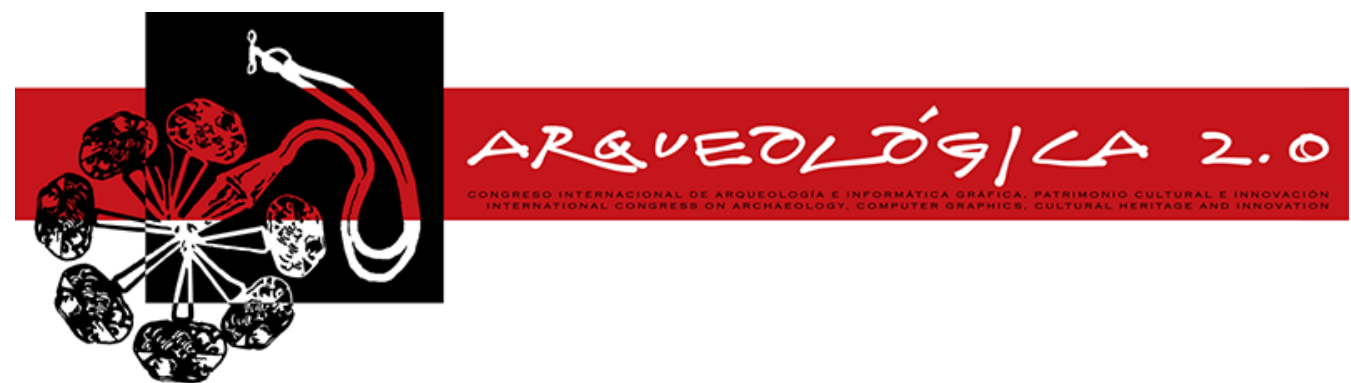

Proceedings of the $8^{\text {th }}$ International Congress

on Archaeology,

Computer Graphics,

Cultural Heritage and Innovation

'ARQUEOLÓGICA 2.0'

in Valencia (Spain),

Sept. 5-7, 2016

DOI: http://dx.doi.org/10.4995/arqueologica8.2016.3559

Received: 01/03/2016

Accepted: 11/04/2016

\title{
THE SURVEY, THE REPRESENTATION AND THE STRUCTURAL MODELING OF A DATED BRIDGE
}

\author{
EL LEVANTAMIENTO, LA REPRESENTACIÓN Y EL MODELADO ESTRUCTURAL DE UN PUENTE ANTICUADO \\ Serena Artese ${ }^{\mathrm{a},{ }^{,},}$, José Luis Lerma ${ }^{\mathrm{b}}$, Giuseppe Zagari ${ }^{\mathrm{a}}$, Raffaele Zinno ${ }^{\mathrm{a}}$ \\ ${ }^{a}$ Department of Informatics, Modeling, Electronics and System (DIMES), University of Calabria, Cubo 39/C, Via Ponte Pietro Bucci, \\ 87036 Rende (CS), Italy. serena.artese@unical.it; giuseppe.zagari@unical.it; raffaele.zinno@unical.it \\ ${ }^{\mathrm{b}}$ Photogrammetry \& Laser Scanner Research Group (GIFLE), Department of Cartographic Engineering, Geodesy and Photogrammetry, \\ Universitat Politècnica de València, Valencia, Spain. jllerma@cgf.upv.es
}

\begin{abstract}
:
The in opera concrete bridges characterize often the landscapes crossed by old roads and railways. In particular the arch bridges represent a product of human genius and, in some cases, of his art. In the last few years, at the SmartLab laboratory of the University of Calabria, there were developed activities in the field of surveying, monitoring and representation of structures. In the framework of these activities, Geomatics techniques for the surveying of bridges are widely used since 2014. The results of the measurements are used for documentation and representation purposes, as well as for the reconstruction of the constructive procedures. The finite element modeling of the structures has been obtained to simulate their behavior in case of earthquake. This article describes the activities relating to a bridge dated back to the 50s of the twentieth century: it is an arch bridge made of reinforced concrete. The surveying is aimed to determine the exact reconstruction of the geometry, the identification of the foundation settlement as well as the Finite Element Modeling (FEM) in order to allow structural identification and reverse engineering process. The instruments and techniques used for surveying and modeling operations, along with the deviations between models and "as built" are described.
\end{abstract}

Key words: laser scanning, cultural heritage, 3D reconstruction, reverse engineering, bridge, FEM model, vibration modes, structural identification

\section{Resumen:}

Los puentes de hormigón in opera caracterizan a menudo los paisajes atravesados por los antiguos caminos y las vías férreas. En particular, los puentes de arco, representan un producto del ingenio humano y, en algunos casos, de su arte. En los últimos años, en el laboratorio SmartLab de la Universidad de Calabria, se desarrollaron actividades en el campo de la topografia, el monitoreo y la representación de estructuras. En el marco de estas actividades, las técnicas geomáticas relativas al levantamiento de puentes se utilizan ampliamente desde 2014. Se utilizan los resultados de las mediciones con fines de documentación y de representación, así como para la reconstrucción de los procedimientos constructivos. La modelización mediante elementos finitos de la estructura se ha obtenido para simular su comportamiento en caso de terremoto. El artículo describe las actividades relativas a un puente que data de los años 50 del siglo XX: es un puente en arco de hormigón armado. El levantamiento está dirigido a la reconstrucción exacta de la geometría, la identificación de asentamiento de la cimentación y el modelado de elementos finitos que permiten la identificación de estructuras y el proceso de ingeniería inversa. Se describen las herramientas y las técnicas utilizadas durante el levantamiento con escéner làser y las operaciones de modelado, junto con las desviaciones entre los modelos y el como fue construido "as built".

Palabras clave: láser escáner, patrimonio cultural, reconstrucción 3D, ingeniería inversa, puente, modelo de elementos finitos, modos de vibración, identificación estructural

*Corresponding Author: Serena Artese, serena.artese@unical.it 


\section{Introduction}

Several reinforced concrete arch bridges cast in situ have been realized during 19th and 20th centuries. The use of precast elements, of prestressed concrete and the increase of the mechanical properties of materials has made so that this technique, involving the use of arch frames typically fabricated from wooden timbers and boards, was gradually abandoned.

Still today, the "in opera" concrete bridges characterize often the landscapes crossed by old roads and railways. In particular the arch bridges represent a product of human genius and, in some cases, of his art. For this reasons, the in opera concrete bridges belong to cultural heritage and deserve to be investigated. Furthermore, several reinforced concrete arch bridges are still used and controls are needed, for evaluating their suitability to withstand the loads to which they are subjected daily.

In the last few years, at the SmartLab laboratory at the University of Calabria, activities were developed in the field of surveying, monitoring and representation of structures. In the framework of these activities, geomatics techniques have been used widely for the surveying of bridges since 2014 .

The authorities in charge of maintenance of the road structures (ANAS - National Agency for Roads, Regions, Provinces) have to face different problems for both new and dated structures.

In the first case, the working plans and the design drawings are used, so the goal of the surveys is to get the as built, to be compared with the project, for testing activities and accounting of work performed, as well as for documentation purposes (Fuchs et al. 2004, Zogg and Ingensand, 2008).

In the case of dated structures, very often it is not possible to obtain the design documents, so the survey is also used to reconstruct the manner of execution and disassemble the organism into the structural elements that were considered and dimensioned during the design phase (Lubowiecka et al. 2009). The results of the measurements are used for documentation and representation purposes, as well as for the reconstruction of the constructive procedures. The finite element modeling of the structures is widely used to simulate their behaviour in case of earthquake. The analysis of the calculation results allows us to identify the critical parts of the structures, possibly to be reinforced, and which present the maximum stress.

The surveys and representations are used also for the identification of degraded areas, detachments of bar coverage, on which we must intervene with actions of recovery and restoration.

An accurate finite element model is used, finally, for the identification of the vibration modes of the structure independently from external stresses, necessary for predicting its behavior under dynamic loads.

The following describes the operations performed for surveying and modeling of a bridge located on a road managed by the Province of Cosenza, Italy. The bridge dates back to the 50s of the last century: it is an arch bridge made of reinforced concrete. The survey is aimed at the exact reconstruction of its geometry, the identification of foundation settlement and finite element modeling, to simulate the behavior of the structure under seismic conditions.

\section{Instruments and methodology}

It was decided to use laser scanner technology, with an integrated camera, and a GPS for the georeferencing, in order to acquire large amounts of geometric and photographic data in a short period. The choice of the laser scanner to perform a survey in a satisfactory manner, with adequate precision and completeness of representation, must take into account, in addition to the mandatory considerations about the accuracy and the flow rate, some other practical-operational features (Ĉapo et al. 2011; Deruyter et al. 2009; Lerma et al. 2008; Tang and Akinci 2011). Fundamental to this is the evaluation of the number of scans necessary for the complete visibility of all parts of the object to be surveyed, and the conditions in which it must operate to perform the survey.

The laser scanner RIEGL VZ 1000 was used, with the following characteristics:

- Accuracy of single point: $\pm 8 \mathrm{~mm}$.

- Range: from $1 \mathrm{~m}$ to $1400 \mathrm{~m}$.

- Sampling frequency: until 122.000 points/sec.

- Field of view: $100^{\circ}$ (Vertical) - $360^{\circ}$ (Horizontal).

- Leveler and magnetometer.

- GPS receiver.

- Nikon D610 Camera with a 20 mm calibrated lens.

- Acquisition of pulse waveform return.

This last characteristic allows us to discriminate the terrain or an object from the vegetation that covers it. The processing of data from the laser scanner was performed with the RiscanPro ${ }^{\circledR}$ and Geomagic $₫$ software.

It must be noted that the laser scanner is equipped with a GNSS receiver which allows just an approximate positioning of the station (single point positioning) with the use of the code and the method of pseudoranges, whereby, to obtain an accurate geo-referencing, we used a Leica Viva dual-frequency receiver, capable of receiving the signals from GPS and GLONASS constellations. For the data processing of satellite measurements in differential mode, we made use of data acquired by the permanent station GNSS positioned at the Laboratory of Geomatics, Department of Civil Engineering - University of Calabria, which captures data at a frequency of one $\mathrm{Hz}$. The processing of the acquired data, performed with the Leica Geo Office $®$ software, provided the coordinates of the station points with centimeter accuracy.

\section{The survey of Caprovidi bridge}

The Caprovidi bridge, in place at S. Angelo, at the town of Cetraro (CS), is located at km $1+900$ of Provincial Road number 26. It is a reinforced concrete arch bridge, cast in place, with two frame piers convergent with the plinths of the supporting arch (Fig. 1).

The VZ 1000, used with the compensator, equipped with the external Nikon D610 camera and the GNSS receiver, was configured with a resolution of $0.08^{\circ} / \mathrm{pt}$, 
corresponding to 7 points per meter at a distance of 100 $\mathrm{m}$, and a scan rate of 120,000 points per second.

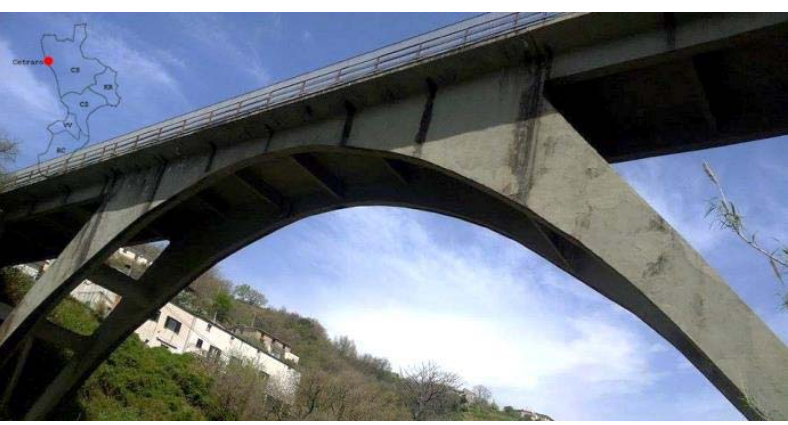

Figure 1: The Caprovidi bridge.

Some details of the bridge were scanned with a resolution of $0.007^{\circ} / \mathrm{pt}$, corresponding to 82 points per meter at a distance of $100 \mathrm{~m}$, in order to reconstruct their geometry in a more accurate way. For georeferencing, the station coordinates obtained by GNSS were used, combined with indications of the magnetometer which is fitted to the laser scanner. Three scans were used (Fig. 2). Due to the topographic situation, in fact, it was not possible to obtain access to the area on the hydraulic right side of the river, for which some parts were not visible; the thick vegetation was also an obstacle which prevented scanning of some parts of the bridge abutments. Lastly, the support bases of the arch and of the $\mathrm{Y}$ piers are covered by backfill terrain. For each scan, a partial spatial overlap with the adjacent ones was planned.
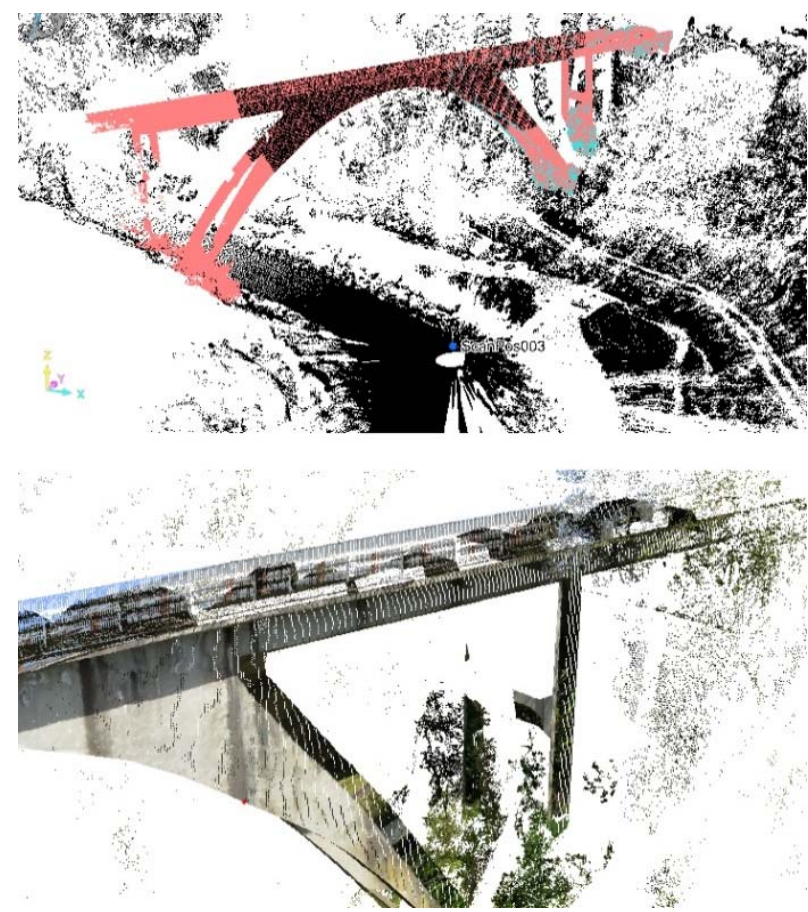

Figure 2: Top: Union of scans. Bottom: detail of a colored point cloud.

Two scans were performed from the two sides of the bridge; for the third acquisition, performed under the deck, the instrument was positioned with an inclination of $90^{\circ}$. Also in this case, some details of the bridge were scanned with more definition. Cylindrical targets were positioned, having a diameter of $14 \mathrm{~cm}$, to facilitate the alignment of the scans in the data processing.

The reference system of the first station was used also for the subsequent ones. The targets, having reflecting surface, were positioned in such a way as to be easily and clearly visible in the scans. For accurate georeferencing, acquisitions were performed with a dualfrequency GNSS receiver, post-processed along with the data collected from the fixed permanent station. The filtering and the reduction of the point clouds were particularly delicated. While having the possibility of discriminating the return pulses, a thorough job on the part of the operator was necessary, since the automatic procedures were influenced by the vegetation and the geometry of the work. In the absence of the project drawings, the survey was aimed at the reconstruction of the structure, but also at obtaining the initial design (reverse engineering). For this reason, two 3D models were created: the first was obtained directly from the mesh generated after the steps of registration, filtering and decimation; the second one is the geometrically regular model, which should constitute the project work. The first model can be used for documentation, while the second is used as a basis for structural modeling. Recent applications aim at obtaining the finite element model directly from the point cloud (Castellazzi et al. 2015; Vosselman et al. 2004). In Figure 3, the mesh obtained after the elimination of the vegetation is shown. There is an evident lack of information, especially in the areas surrounding the foundations.

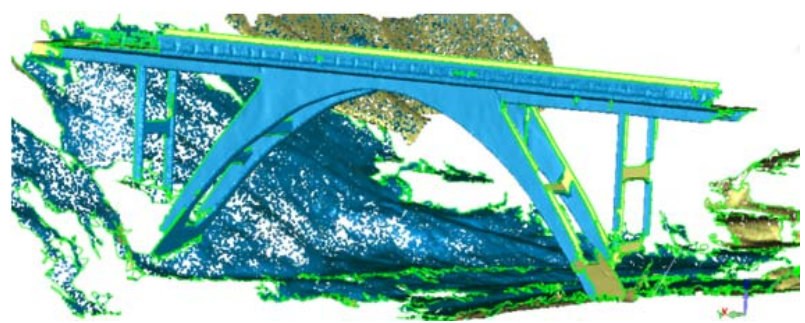

Figure 3: Mesh without vegetation.

The on-site research and detailed measurements allowed us to integrate the results of the laser scanner survey and to develop the likely geometric model of the project, shown in Figure 4 with the main structural elements highlighted in different colors.

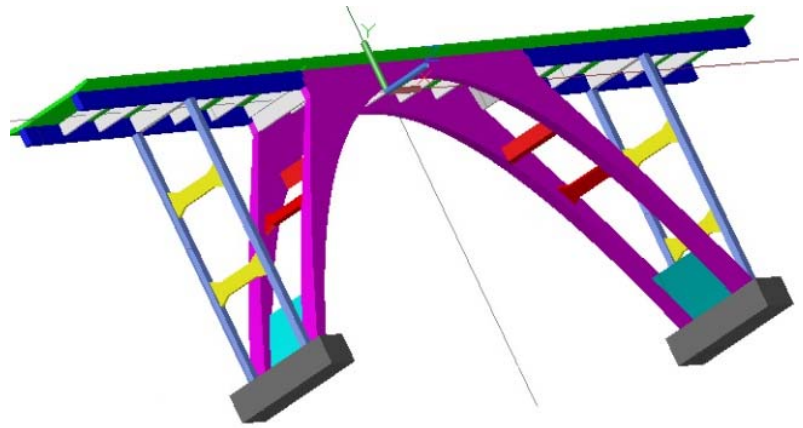

Figure 4: The geometric model.

The red and blue areas identify irregularities generally due to detachment of material. The very high values of the maximum and minimum deviations are due to the presence of some unfiltered points, automatically assigned by the software to a wrong surface. 
Figures 5 and 6 show the deviations between the ideal geometric model and the point cloud. It can be observed that the deviations are typically of centimetric order, within the manufacturing tolerances for this kind of structure (cast on site).

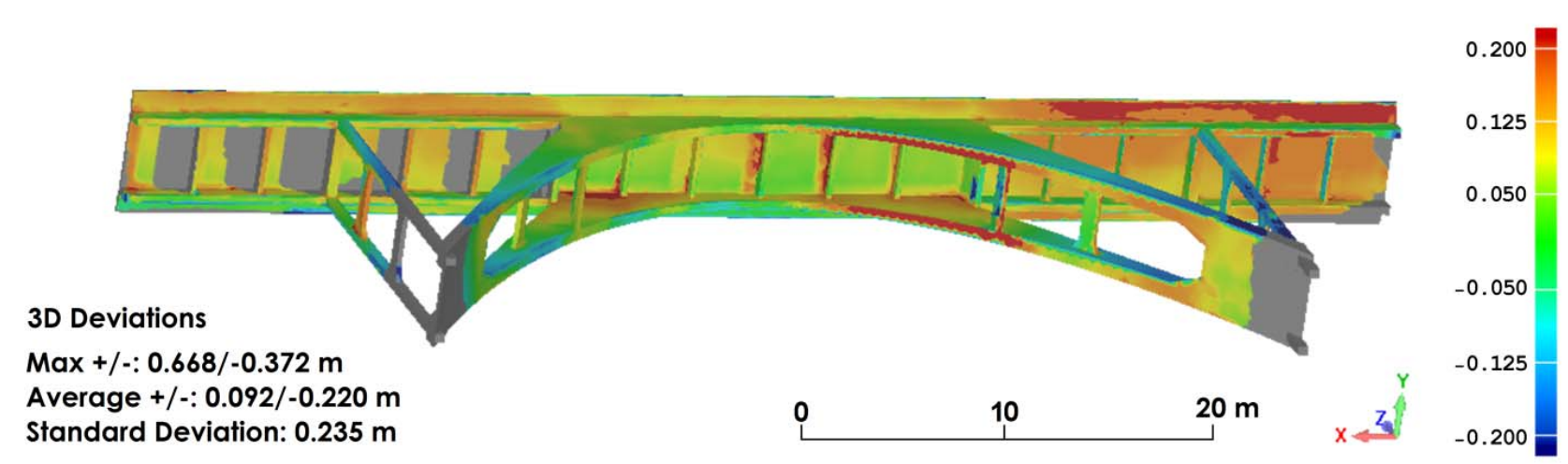

Figure 5: Deviations points-model.

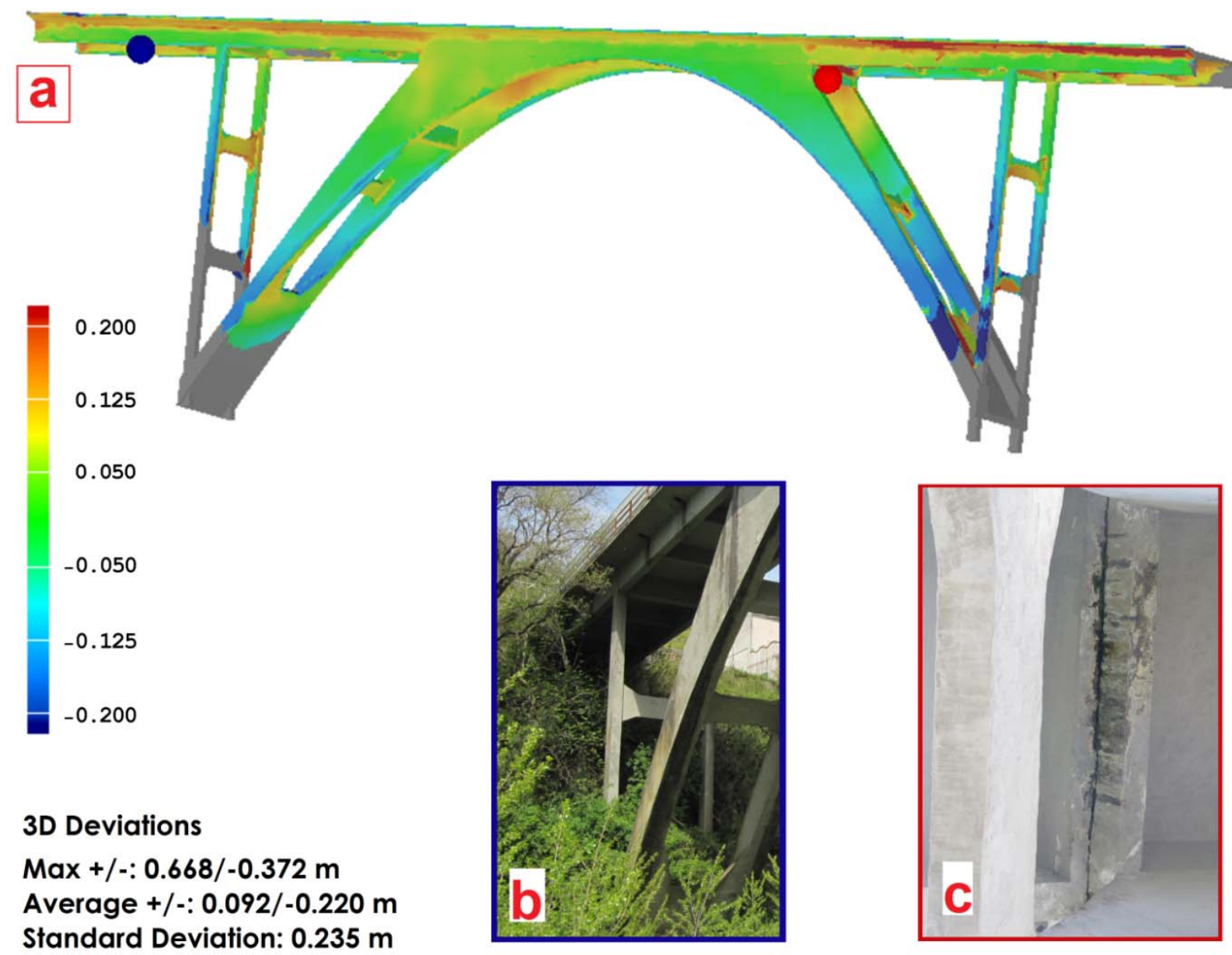

Figure 6: Deviations points-model (a) in correspondence to vegetation (b, blue) and deteriorated areas (c, red).

During vectorization, we proceeded to eliminate eventual interference between the various simple solids that form the overall volume.

\section{The FEM Analysis}

The model so obtained, in this case, was used for the dynamic identification, a very useful procedure also for detecting possible damage to the structure.
The geometrical model was converted into the finite element model (FEM) and analysed using the Abaqus ${ }^{\circledR}$ (ABAQUS 2014), structural analysis software which through automatic procedures imports the vectorized graphic model and converts it into a finite element mesh, in this case 4-node tetrahedral elements with only 3 degrees of freedom per node (Ux, Uy, Uz) 
This type of element was mainly used to generate the structure and the regular mesh, without losing accuracy, even in zones with variable thickness (Figs. 7 and 8).

The outputs of the structural calculations performed on the finite element model, were compared with those obtained through in situ measurements, obtained by positioning a minimal set of 8 piezo electric unidirectional transducers with a sensitivity equal to $10 \mathrm{~V} / \mathrm{g}$ (Volt per standard gravity) arranged in a suitable way in order to catch the main aspects of the structural dynamics of the bridge. These sensors identified the real vibration modes of the structure subjected to ambient noise and uncontrolled stress, by using the Frequency Domain Decomposition (FDD) technique (Brincker et al. 2000, Gentile, 2006).

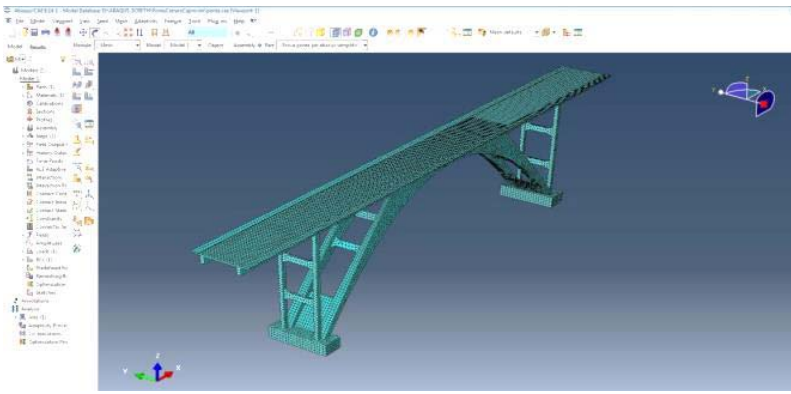

Figure 7: FEM model generated automatically from the CAD model.

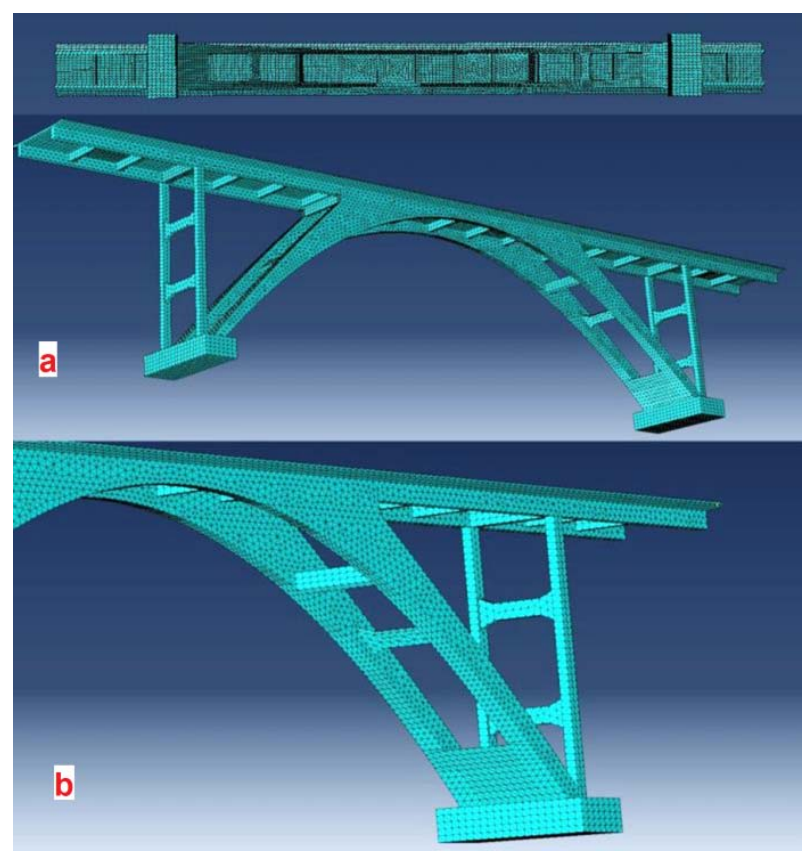

Figure 8: a) bottom views of the FEM model. b) enlargement.

For seismic analysis, a bridge is treated as an oscillating system. The way an oscillating system moves can be decomposed in several patterns of motion, called normal modes. Generally, the first modes are sufficient to describe the behavior of the structure. In our case, the first three modes have been represented in the Figures 9 and 10 . The first mode is characterized by movements in horizontal direction, the second one in vertical direction, the third one by a torsional movement.
The analysis results are in agreement with the measurements in situ and specific procedures were not necessary for updating the identification of the mechanical characteristics of the structure (Artese et al. 2015).
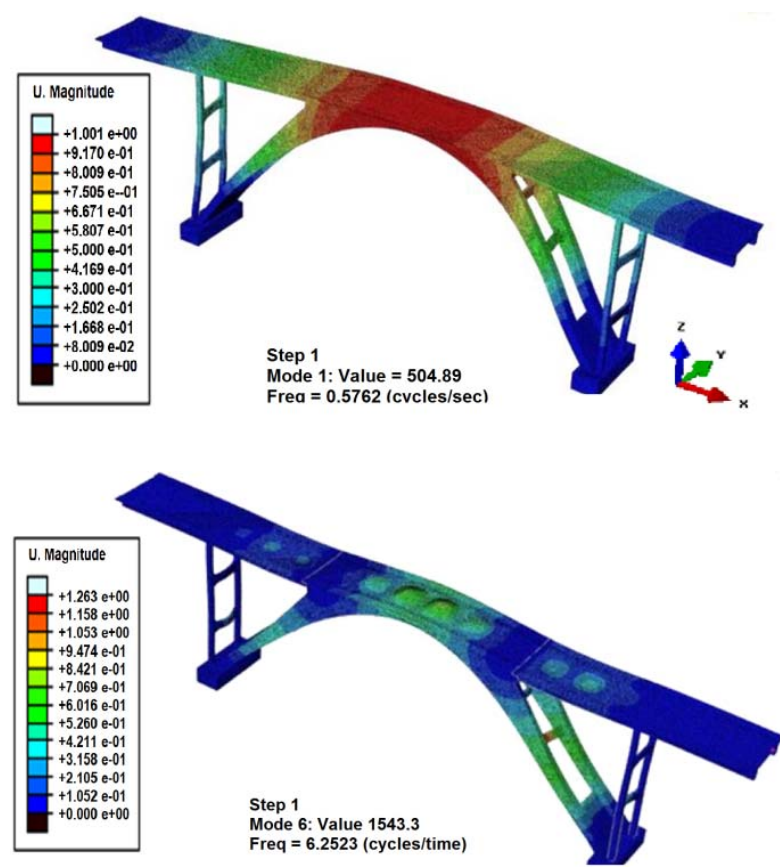

Figure 9: Top: $1^{\text {st }}$ vibration mode. Bottom: $2^{\text {nd }}$ vibration mode.

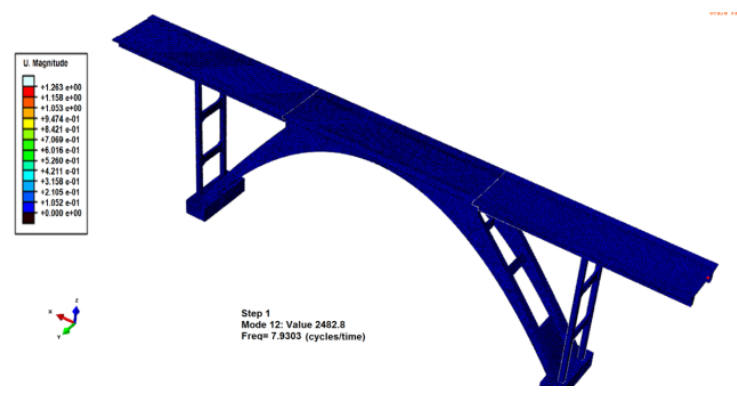

Figure 10: $3^{\text {rd }}$ vibration mode

\section{Future activities}

Another activity regards the ancient constructions in brick masonry and stones, which present special problems, and several examples of which are present and still used along the roads (Riveiro et al. 2011).

A very interesting construction is the Sant'Angelo Bridge, also known as the Hannibal Bridge.

It is a Roman bridge dating from the $2^{\text {nd }}$ century B.C., located between the towns of Altilia and Scigliano, in the Province of Cosenza, Italy (Fig. 11).

The scans of the construction were performed, while the building of the model is still in progress.

Like in the previous case, the activities of survey (Fig. 12) were carried out with two techniques: Riegl VZ 1000 terrestrial time of flight laser scanner to acquire the geometric characteristics, and GNSS receiver for georeferencing. 
To scan the bridge in its entirety, five stations were chosen. The scans carried out provided very high density point clouds (Figs. 13 and 14), which describe the surface of the object with extreme detail. For the connection of individual scans cylindrical target were used, and common points (tie points).

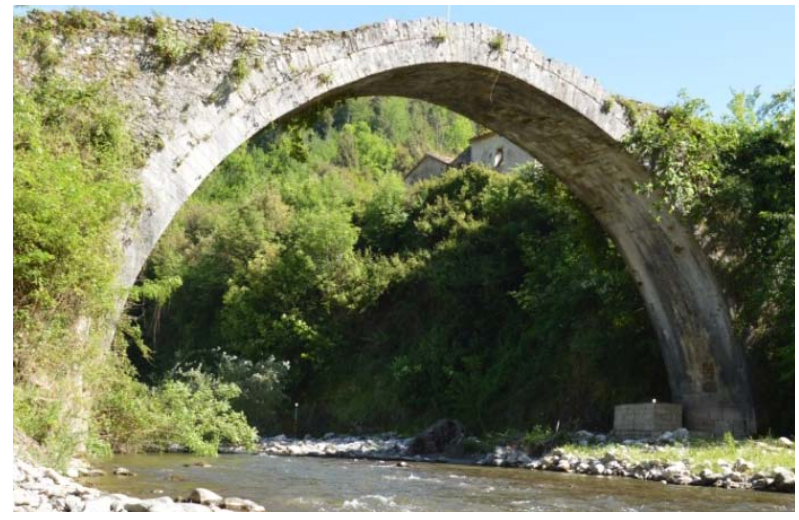

Figure 11: The Hannibal Bridge.
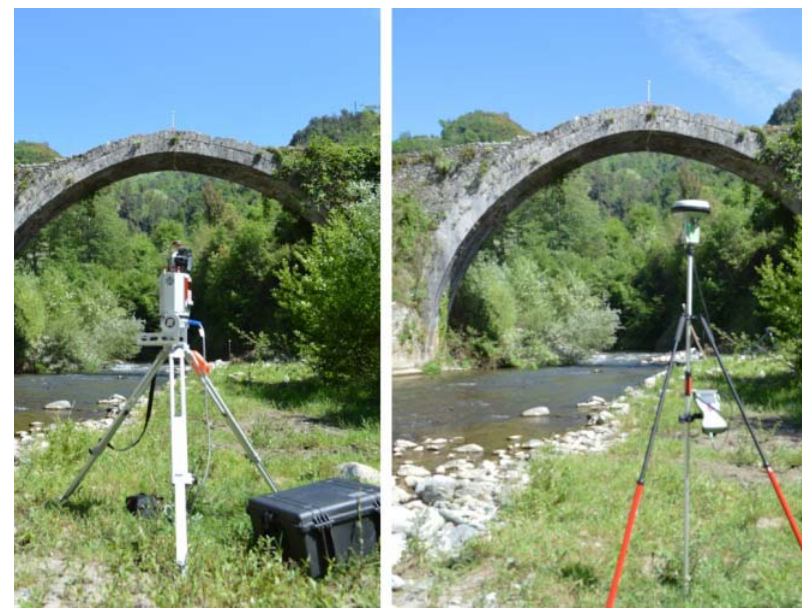

Figure 12: Survey of the Hannibal Bridge with Laser Scanner and GNSS receiver.

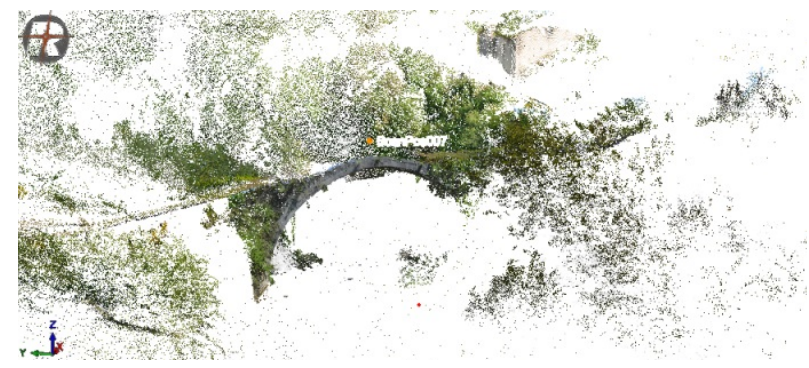

Figure 13: The union of the scans of Hannibal Bridge and Savuto Valley.

The aim of the future activities is to obtain the model of the bridge inserted in the surrounding landscape. This study will be performed in the framework of a research regarding the ancient Roman road "Via Annia", whose path followed the valley of the Savuto river.

\section{Conclusions}

The activities of surveying and modelling of a reinforced concrete arch bridge, cast in place, have been described. The aim was the documentation and the representation of the manufact, as well the reconstruction of the constructive procedures.

The data processing allowed to create two 3D models: the first was obtained directly from the mesh generated; the second one is the geometrically regular model, obtained through interpolating planes, which should constitute the project work.

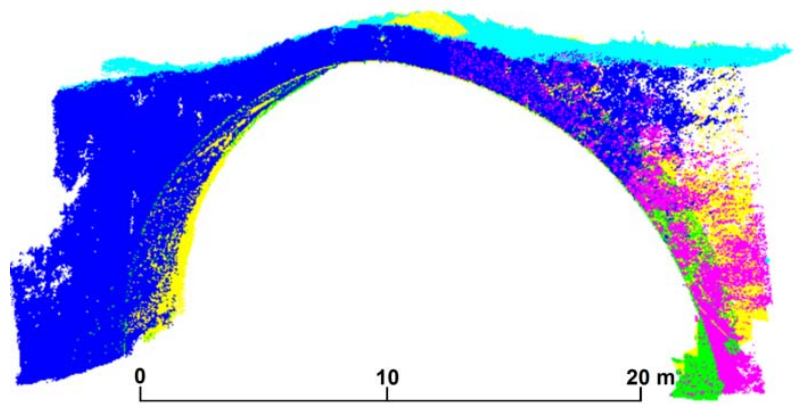

Figure 14: The union of the scans of Hannibal Bridge.

The deviations between the ideal geometric model and the point cloud were typically of centimetric order, within the manufacturing tolerances for this kind of structure (cast on site). The achieved accuracy fits the requirement for a reliable structural analysis. In this case, indeed, the finite elements used to describe the structure and perform the structural analysis, have dimensions of few decimeters, so a few centimeter accuracy is quite sufficient.

The geometrically regular model allowed us to build a finite element model (FEM) of the bridge, in order to obtain the vibration modes and to simulate their behavior in case of earthquake, or when the object is subjected to dynamic changes.

The outputs of the structural calculations performed on the FEM were in agreement with those obtained through in situ measurements

The results obtained confirm the usefulness of geomatics techniques both for the documentation and for the structural modeling of modern bridges.

\section{Acknowledgements}

The authors are thankful to SMARTLab (Structural Monitoring, Structural Advanced Materials, Structural Rehabilitation, Structural Testing) at the University of Calabria, for the technical and scientific support as well as Ing. Angela Miceli, Ing. Paolo Talarico, and Ing. Assunta Venneri for the collaboration during the survey of the bridges.

\section{References}

ABAQUS 6.14. Analysis User's Manual. Online Documentation Help: Dassault Systèmes. 
ARTESE, S., MICELI, A., TALARICO, P., VENNERI, A., ZAGARI, G. and ZINNO, R., 2015. Ponti antichi e moderni: utilizzo di tecniche geomatiche per il rilievo, la rappresentazione e la modellazione strutturale. Atti 19a Conferenza Nazionale ASITA, 29-30 Settembre - 1 ottobre 2015, Lecco - Polo di Lecco del Politecnico di Milano - ISBN 978-88941232-2-7.

BRINCKER, R., ZHANG, L.M. and ANDERSEN, P., 2000. Modal identification from ambient response using Frequency Domain Decomposition. Proc. $18^{\text {th }}$ Int. Modal Analysis Conference (IMAC), San Antonio, 2000.

ĈAPO, A., BABIÜ, L., and PRIBIPEVIÜ, B., 2011. Application of a 3D terrestrial laser scanner in a survey of a railway bridge" Sava Jakuševac". In5th International Conference on Engineering Surveying.

CASTELLAZZI, G., D'ALTRI, A.M., BITELLI, G., SELVAGGI, I. and LAMBERTINI, A., 2015. From laser scanning to finite element analysis of complex buildings by using a semi-automatic procedure. Sensors, 15(8), 18360-18380; doi:10.3390/s150818360

DERUYTER, G., HENNAU, M., DE WOLF, V. and DEWULF, N., 2009. Approach for comparing design and as built models based on data acquisition using a 3D terrestrial laser scanner, a case study. In 4th International workshop on 3D Geo-information, pp. 101-116.

FUCHS, P.A., WASHER, G.A., CHASE, S.B., and MOORE, M., 2004. Applications of Laser-Based Instrumentation for Highway Bridges, Journal of Bridge Engineering , ASCE, November/December, pp. 541-549.

GENTILE, C., 2006. Modal and structural identification of a RC arch bridge. Structural engineering and mechanics.Vol 22, n.1, pp 53-70.

LERMA, J.L., VAN GENECHTEN, B., HEINE, E., and SANTANA, M., 2008. Theory and practice on Terrestrial Laser Scanning. Editorial de la Universidad Politécnica de Valencia, Valencia.

LUBOWIECKA, I., ARMESTO, J., ARIAS, P. and LORENZO, H., 2009. Historic bridge modelling using laser scanning, ground penetrating radar and finite element methods in the context of structural dynamics. Engineering Structures, 31, 2667-2676.

RIVEIRO, B., MORER, P., ARIAS, P. and DE ARTEAGA, I., 2011. Terrestrial laser scanning and limit analysis of masonry arch bridges. Construction and building materials, 25(4), 1726-1735.

TANG, P., and AKINCI, B., 2012. Automatic execution of workflows on laser-scanned data for extracting bridge surveying goals. Advanced Engineering Informatics, 26(4), 889-903.

VOSSELMAN, G., GORTE, B. G., SITHOLE, G. and RABBANI, T., 2004. Recognising structure in laser scanner point clouds. International archives of photogrammetry, remote sensing and spatial information sciences, 46(8), 33-38.

ZOGG, H.M., and INGENSAND, H., 2008. Terrestrial Laser Scanning for Deformation Monitoring -Load Tests on the Felsenau Viaduct $(\mathrm{CH})$. The International Archives of the Photogrammetry, Remote Sensing and Spatial Information Sciences, Volume XXXVII, Part B5, pp. 555-562. 